\title{
Collaborative Learning in College English Teaching at Sport Universities
}

\author{
W.LIU \& S.ZHOU \\ School of Sport Management and Communication, Capital University of Physical Education and Sports, \\ Beijing, China
}

\begin{abstract}
Collaborative learning is used for the English language teaching of college students at sport universities. It is innovative in that it involves the students and teachers co-work to master knowledge. It involves: 1) the forms of collaborative learning in teaching at sport universites 2) the challenges of collaborative learning 3) the framework of collaborative learning. A greater aspect of collaborative learning mode used here is the attachment of a higher level of group work and film simulated training.
\end{abstract}

KEYWORD: collaborative learning; college student; volunteer English language training; sports events

\section{INTRODUCTION}

Collaborative learning has been an interest of mine since beginning my career as a teacher six years ago. I strongly hold that students will often learn things better from their peers than from their teachers, and that they can learn a lot from teaching things to their peers as well. I have had several discussions with some colleagues at my school. One of them thought that it might be not suitable for general English courses in our university since our university was a physical education centered university and most of the students tend to be poor in English. She thought I used too much of it and that it wasn't effective; I thought it was important. Our disagreements ended up in my attempt to apply collaborative learning to college student volunteer English training since this training was involved in the first students majoring in sports management. Their English competence is much better than other majors. There would be students from better backgrounds. There are no regular courses of such training in Beijing but just accumulative training of about ten to fifteen sessions. This was encouraging, but I still seek to find more concrete evidence that group work and collaboration between students will not only be effective and beneficial in the educational realm for students, but that it will enhance many areas of their lives, for many of the students would be physical education teachers in schools. I would like to study the effects of collaborative groups in training.

\subsection{Review of Literature}

\subsubsection{Collaborative Learning}

\subsubsection{Definitions of Collaborative Learning}

In 1992, Goodsell, gave her definition (Goodsell, Anne S.1992) in the introduction of Collaborative Learning in her Collaborative Learning: A Sourcebook for Higher Education. She believes that broadly defined, collaborative learning reforms classroom learning by changing students from passive recipients of information given by an expert teacher to active agents in the construction of knowledge. This type of learning takes many forms and is called many names including cooperative and collaborative learning.

In the first section of the book, Smith and MacGregor define "Collaborative learning" (Goodsell, Anne S.1992) as an umbrella term for a variety of educational approaches involving joint intellectual effort by students, or students and teachers together. In most collaborative learning situations students are working in groups of two or more, mutually searching for understanding, solutions, or meanings, or creating a product. There is wide variability in collaborative learning activities, but most center on the students' exploration or application of the course material, not simply the teacher's presentation or explication of it. Everyone in the class is participating, working as partners or in small groups. Questions, problems, or the challenge to create something drive the group activity. Learning unfolds in the most public of ways. 
Seven years later Dillenbourg gave the broadest (but unsatisfactory) definition (Dillenbourg P.,1999) of "collaborative learning" is that it is a situation in which two or more people learn or attempt to learn something together.

\subsubsection{Who advocated CL?}

In 1996, Dillenbourg, Blaye, O'Malley and Baker developed a theme on collaborative learning. In 1996, 20 scholars gathered from the disciplines of psychology, education and computer science. They attended workshops. Part of a research program was entitled 'Learning in Humans and Machines' (LHM), launched by Peter Reimann and Hans Spada, and funded by the European Science Foundation. This program aimed to develop a multidisciplinary dialogue on learning, involving mainly scholars from cognitive psychology, educational science, and artificial intelligence (including machine learning). During the preparation of the program, Blaye, O'Malley, Baker and Peter developed a theme on collaborative learning. When the program officially began, 12 members were selected to work on this theme.

\subsubsection{Significant studies}

Smith and MacGregor (1992) pointed out the approaches of cooperative learning. It includes problem-centered instruction, guided design, case studies, simulations, speaking groups, peer teaching, workshops, discussion groups and seminars, learning communities.

Busher (2005) conducted a study on collaboration. This study defines their area of study as a learning community, and they can be "as large as a whole school or as small as a classroom."

Collaborative learning has been found to give students the benefits of student motivation and confidence (Felner et al, 2007).

Felner, Seitsinger, Brand, Burns, and Bolton (2007) made their researches on the "Project on High-Performing Learning Communities" to determine their effectiveness within schools, especially in a middle school. Felner et al pays attention on the importance of personalizing the school hoping "[engaging] diverse, socially, and economically disadvantaged students, in middle and high schools, to improve academic performance, reduce dropout rates, enhance developmental outcomes, and close equity gaps."

A collaborative group in school consists of a "reciprocal interaction in which ideas and perspectives are explored and exchanged, solutions are elaborated and justified, and exchanges are supportive and coordinated" (cited in Harris 2008). Sports events volunteer training

\subsection{The status quo of College English Teaching at Sport Universities}

Usually the host city of those international sports events will determine which universities should choose students to be volunteers. And the teachers in those universities will hold several lectures on how to be a good college student volunteer. In my university, we have ten-fifteen sessions.

\subsubsection{The current problems existing in teaching}

It's not a systemic training. No schools in Physical Education Universities offer courses on the training in the sports events. The regular courses are not so related to the sports events. There is a lack of systematical training materials for a specific sports event and a routine and comprehensive training package not suitable to the student volunteers due to their limited free time.

\subsubsection{What specific areas of knowledge should be included in teaching?}

In China there are many kinds of sports events, say the Olympic Games, the Asian Games, International University of Sports Federation, Snooker China Open, and China Open Tennis. Also there are different positions for the volunteers. What fields of knowledge should each position need?

\subsubsection{Significant studies}

The study by Mohan and Smith (Nunan, 1992) is on a collaborative learning research in graduate adult education course. The students are below their language proficiency. The study demonstrates how collaboration interacts between the instructor and the students and thus enables the students to outperform their competence. Besides, the small-group work, group tutorials and assignments provided in the study enabled the students to maintain a sense of coherence.

\section{RESEARCH QUESTIONS}

Central question: How could collaborative learning be applied in college student volunteer training in sports events?

\section{Sub-questions}

1. To what extent is CL effective at delivering college student volunteer English language training?

2. What approaches of collaborative learning can be used in college student volunteers?

\section{METHOD}

In order to explore the impact of volunteer training 
learning outcomes in collaborative settings, I'll use quasi-experimental design in which two sections of introductory level classes are going to be taught concurrently by the same instructor. The classes are going to consist of identical instructional material and course layout and design. The control group is going to be taught using standard collaborative learning techniques and the experimental group is going to be set up in an identical fashion.

\subsection{Participants and Design}

Subjects in this study consist of two groups of participants from the freshmen majoring in sports management in my university. Each group (experimental and control) initially consist of 30 students. There is no knowledge of course content or experimental/control group differences prior to commencement of the course.

\subsection{Control Group}

Success in the course is based on student participation in group activities; attendance and two multiple choice exams which will measure learning. The exams will determine student success in terms of this experiment. The exam questions will be taken from a test bank that accompanies the book of choice. Each post exam contains questions from the pretest, as well as others. The improvement on these repeated questions will show learning and retention.

\subsection{Experimental Group}

The experimental group is going to be taught exactly the same as the control group, with all assignments, activities, and exams identical in content. However, the grading of these classes is going to be slightly different. In the experimental class, 15 percent of the students' overall course grade comes from the performance of his or her partner. The groups are going to be treated differently in no other way. An outsider who is not aware of the experimental differences observed these classes on one occasion, and reports no differences in style or content.

\subsection{Control/Experimental Group Demographics}

The control group consisted of 30 students. In the control group there are 15 males and 15 females, 15 of who are from Beijing and 15 of who are from other parts of the country. The experimental group consists of 30 students. In the experimental group there are 10 males and 20 females, 20 of who are from Beijing and 10 of who are from other parts of the country.

\section{Pre-test}

Students are going to be assigned a teammate based on their scores on a preliminary exam, which serve to determine their ability level prior to instruction in this course. This exam is multiple choice format, covering questions related to definitions or understandings of volunteer English language in sports events. Application questions are excluded from the exam on the basis that students could not adequately answer those questions without having knowledge of concepts first. The exam consisted of 25 questions.

\subsection{Matching Students}

Approximately $50 \%$ of the groups will be made up of heterogeneous or mixed ability pairs, and the other $50 \%$ will be made up of homogenous or similar ability pairs. To determine the ability level, I'll check the statistics from the pre-test. Using simple statistical analysis such as mean and standard deviation, I'll measure "how much difference" constitutes a heterogeneous pair. The standard deviation for both classes was between 4 and 5 points, so homogenous pairs have two students that score within 4 points difference from one another, and heterogeneous pairs consist of partners who are more than 5 points difference from one another. Based on this criterion, partners will be selected randomly.

\subsection{Analysis of Data}

Data are analyzed using the Statistical Software Package for the Social Sciences (SPSS 14.0). The following independent variables will be examined: group placement experimental or control, pairing (heterogeneous ability pairs or homogeneous ability pairs).

\section{IMPLICATIONS}

A more relaxing atmosphere is created in the classroom, especially within the group, where students lower their anxiety of speaking in front of the whole class. Most important of all, by engaging active activities, students can learn thinking, reasoning, problem-solving, and decision-making skills.

Finding the barriers to large-class CL will help teachers to work out more systematic and effective teaching strategies for CL, which can be applied by other teachers. From group building to leader selecting to activity organizing, every step should be carefully designed with the guidance of CL theories.

In order to explore the impact of CL on college student volunteer English language training, I must give them two oral tests during the pretest and the 
posttest period, and then compare and analyze the relative data I collect, which means the oral test is very important to ensure assessment accuracy and objectiveness. Thus, it deserves more care and energy to think how to design tests with the help of peers.

\section{REFERENCES}

[1] Busher, H. (2005). The project of the other: Developing inclusive learning communities in schools. Oxford Review of Education 31(4), 459-477.

[2] Campbell, D. T., \& Stanley, J. C. (1963). Experimental and Quasi-experimental designs for research. Chicago: Rand McNally Co.

[3] Dillenbourg P. (1999). What do you mean by collaborative learning?. In P. Dillenbourg (Ed.), Collaborative-learning: Cognitive and Computational Approaches. (pp.1-19). Oxford: Elsevier.
[4] Egan, K. (2008). Learning in depth. Educational Leadership, 66(3), 58-63.

[5] Felner, R., Seitsinger,A., Brand, S., Burns,A, \& Bolton, N. (2007). Creating small learning communities: Lessons from the project on high-performing learning communities on "what works" in creating productive, developmentally enhancing, learning contexts. Educational Psychologist, 42(4), 209-221.

[6] Harris, A., Yuill, N, \& Luckin, R. (2008). The influence of context-specific dispositional achievement goals on children's paired collaborative interaction. British Journal of Educational Psychology, 78(3), 1-20.

[7] Nunan, D. (1993). Collaborative language learning and teaching. London: Cambridge University Press.

[8] Roschelle, J. \& Teasley S.D. (1995) The construction of shared knowledge in collaborative problem solving. In C.E. O'Malley (Ed), Computer-Supported Collaborative Learning. (pp. 69-197). Berlin: Springer-Verlag.

[9] Smith, B. L, \& MacGregor, J. T. (1992). What is collaborative learning?. Collaborative Learning: A Sourcebook for Higher Education. 